\title{
Marcadores RAPD e caracteres morfoagronômicos na determinação da diversidade genética entre acessos de pimentas e pimentões
}

\author{
RAPD markers and morphoagronomic traits in determining genetic diversity among chili \\ peppers and sweet peppers
}

\author{
Fabiane Rabelo da Costa ${ }^{{ }^{*}}$ Telma Nair Santana Pereira ${ }^{\mathrm{I}}$ Cláudia Pombo Sudré \\ Rosana Rodrigues ${ }^{\mathrm{I}}$
}

\section{RESUMO}

A diversidade genética existente em coleções e bancos de germoplasma pode ser estimada por meio de diversos métodos, sendo que a escolha destes depende da disponibilidade dos recursos e da precisão desejada pelo pesquisador. Neste trabalho, marcadores RAPD e caracteres morfoagronômicos foram usados para estimar a divergência genética entre 52 acessos de Capsicum spp. Um total de 57 variáveis binárias geradas pela caracterização morfoagronômica e 84 bandas polimórficas obtidas a partir da análise por RAPD foram analisadas separadamente e em conjunto, permitindo a construção de três dendrogramas. Observou-se a formação de dois grupos principais, tanto na análise morfoagronômica e molecular separadamente, quanto na análise conjunta dos dados. O agrupamento dos acessos pela análise conjunta seguiu o mesmo padrão verificado para a análise molecular, que se constituiu em um grupo formado por acessos de C. baccatum e outro grupo formado pelos acessos de $\boldsymbol{C}$. chinense, $\boldsymbol{C}$. frutescens e C. annuum. Esse agrupamento segue a proposta vigente para a classificação de Capsicum spp. em complexos gênicos. A associação dos métodos permitiu uma melhor distinção entre os acessos, o agrupamento desses em nível de espécie e a conclusão de que não há duplicatas na coleção, demonstrando a importância do uso de diferentes técnicas na caracterização de um banco de germoplasma.

Palavras-chave: Capsicum spp., germoplasma, marcadores moleculares, descritores qualitativos.

\section{ABSTRACT}

The genetic diversity within collections and banks of germplasm can be estimated by different methods and their choice is dependent of the available resources and the desired precision from the researcher. In the present work, RAPD

\begin{abstract}
markers and morph-agronomic traits were used to estimate the genetic divergence among 52 Capsicum spp. accessions. Fiftyseven binary variables from morph-agronomic characterization and 84 polymorphic markers from RAPD analysis were both separately and jointly evaluated and three dendrograms were generated. Two major groups were formed in all analyses. The clusters from the joint analysis were similar to the ones from molecular analysis. One group was formed with only $\mathbf{C}$. baccatum accessions and the other one with $\boldsymbol{C}$. chinense, $\boldsymbol{C}$. frutescens and $\boldsymbol{C}$. annuum accessions. These results were in agreement with the gene pool complexes proposal. The association of these methods allowed a better distinction among the accessions, a cluster formation at species level and a conclusion that there is no duplicates in the collection, showing how important is the use of different methods to characterize a germplasm bank.
\end{abstract}

Key words: Capsicum spp., germplasm, molecular markers, qualitative descriptors.

\section{INTRODUÇÃO}

No intuito de se estimar a diversidade genética presente em uma coleção de germoplasma, os acessos devem ser caracterizados e avaliados. Essa caracterização pode ser morfoagronômica, citológica, bioquímica, fisiológica ou molecular. Independente do método utilizado, o importante é que os resultados possibilitem uma boa distinção dos acessos e permitam identificar duplicatas e também acessos com características relevantes que possam ser de interesse aos diversos programas de melhoramento. A escolha

ILaboratório de Melhoramento Genético Vegetal, Centro de Ciências e Tecnologias Agropecuárias, Universidade Estadual do Norte Fluminense Darcy Ribeiro (UENF). Avenida Alberto Lamego, 2000, Parque Califórnia, 28013-602, Campos dos Goytacazes, RJ, Brasil. E.mail: fabiane@uenf.br. *Autor para correspondência. 
do método a ser utilizado depende da disponibilidade de recursos e da precisão desejada pelo pesquisador (CONTI et al., 2002).

A identificação de um acesso com base apenas em características fenotípicas não oferece total segurança devido à insuficiência ou escassez de polimorfismo, plasticidade ambiental, dependência do estádio de desenvolvimento e dominânciarecessividade. Assim sendo, faz-se necessário um bom conhecimento quanto à extensão da diversidade genética dentro da coleção de germoplasma e quanto ao parentesco entre os acessos, uma vez que tais informações são cruciais para a exploração do germoplasma, focalizando áreas com máxima diversidade genética (HE et al., 1995). O uso de marcadores moleculares é uma alternativa para avaliação desta variabilidade, permitindo a identificação das diferenças entre os materiais (polimorfismo) em nível de DNA, minimizando a interferência ambiental e aumentando a confiabilidade na distinção dos acessos (BASTIANEL et al., 1998).

A caracterização morfoagronômica é feita com base em caracteres que sejam de fácil detecção e mensuração, tenham alta herdabilidade e que sofram pouca influência ambiental. Para o gênero Capsicum, essa caracterização se baseia na lista de descritores do International Plant Genetic Resources Institute (IPGRI, 1995), que sugere a utilização de 21 descritores essenciais de caracterização e dois de avaliação. Diversas coleções de germoplasma de Capsicum têm sido assim caracterizadas, porém, utilizando um número variável de descritores, como mostram os trabalhos de INOUE \& REIFSCHINEIDER(1989), TEIXEIRA(1996), RAMOS et al. (2000, 2001) e SUDRÉ et al. (2005).

A caracterização molecular pode ser feita por meio de diferentes técnicas, entre elas, o RAPD. Esta técnica tem auxiliado a identificação de variabilidade genética em diferentes populações de plantas e coleções de germoplasma. Diversos trabalhos em Capsicum que utilizam RAPD têm demonstrado sua utilidade como fonte de informações filogenéticas na identificação de cultivares, em estudos de genealogia, mapeamento genético, distinção entre acessos, identificação de duplicatas, estimativa de taxa de intercruzabilidade, entre outros (INAI et al., 1993; PRINCE et al., 1995; VAZQUEZ et al., 1996; LIVINGSTONE et al., 1999; RODRIGUEZ et al., 1999; LIN et al., 2000; BAOXI et al., 2000; ENGLE et al., 2001; KALOO et al., 2002; ILBI, 2003; PARAN et al., 2004; SUGITA et al., 2005; RUANET et al., 2005; COSTA et al., 2006). Embora seja um marcador de baixa repetibilidade de resultados, ele tem como principais vantagens a simplicidade de utilização, o baixo custo e a rapidez na geração de resultados, o que o torna eficiente e adequado para ser utilizado em estudos de diversidade genética, em coleções de germoplasma, na distinção de acessos e no reconhecimento de materiais duplicados.

Os objetivos deste trabalho foram analisar a divergência genética entre 52 acessos de Capsicum spp. com base em dados morfoagronômicos e moleculares e estimar a relação entre as distâncias genéticas obtidas com base nos caracteres morfoagronômicos e nos marcadores RAPD.

\section{MATERIAL E MÉTODOS}

Um total de 52 acessos de Capsicum spp., coletados em feiras, em diferentes regiões do Brasil ou doados pela Empresa de Pesquisa Agropecuária do Estado do Rio de Janeiro (PESAGRO-RIO) e previamente identificados botanicamente por SUDRÉ et al (2006) (Tabela 1), foram caracterizados com base em descritores propostos pelo IPGRI (1995) e com base em marcadores RAPD.

A caracterização morfoagronômica foi efetuada em condições de campo, em blocos casualizados, com três repetições e 10 plantas por parcela. Os dados foram obtidos por meio da moda de cada descritor, num total de 30 plantas. Foram estudadas 13 variáveis multicategóricas e duas binárias, sendo considerados descritores essenciais pelo IPGRI (1995): cor do caule, cor da antera, cor da corola, número de flores por axila, posição da flor, hábito de crescimento, cor do fruto no estádio intermediário, cor do fruto no estádio maduro, forma do fruto, epiderme do fruto, cor da semente, número de lóculos, cor da folha cotiledonar, constrição anular do cálice e presença de constrição do fruto. Os dados para cada variável foram tomados seguindo-se os critérios propostos pelo IPGRI (1995). As variáveis multicategóricas foram transformadas em matrizes binárias conforme proposto por CRUZ \& CARNEIRO (2003), resultando em 57 marcas polimórficas e apenas uma monomórfica.

A caracterização molecular, via RAPD, foi realizada a partir de folhas jovens de três plantas por acesso. De cada um dos 52 acessos avaliados, foram colhidas amostras em bulk e o DNA foi extraído, segundo o protocolo proposto por DOYLE \& DOYLE (1987). A amplificação desse DNA foi realizada conforme WILLIAMS et al. (1990). Detalhes sobre os reagentes e o protocolo de amplificação utilizados podem ser consultados em COSTA (2004). Os iniciadores utilizados foram OPAW-02, OPR-06, OPAX08, OPAW-15, OPV-05, OPR-19, OPAV-06 e OPAU-08 (série Operon Technologies). Esses iniciadores foram 
Tabela 1 - Número de registro, identificação e procedência de 52 acessos de Capsicum spp. da coleção de germoplasma da UENF.

\begin{tabular}{|c|c|c|c|}
\hline Acesso & $\mathrm{N}^{\circ}$ UENF & Espécie & Procedência \\
\hline 01 & 1381 & C. annuum var. annuum & PESAGRO/Itaguaí \\
\hline 02 & 1382 & C. annuum var. annuum & PESAGRO/Itaguaí \\
\hline 03 & 1417 & C. baccatum var. pendulum & UFLA/MG \\
\hline 04 & 1418 & C. chinense & UFLA/MG \\
\hline 05 & 1419 & C. chinense & UFLA/MG \\
\hline 06 & 1420 & C. annuum var. annuum & AGROCERES \\
\hline 07 & 1421 & C. annuum var. annuum & AGROCERES \\
\hline 08 & 1422 & C. annuum var. annuum & TOPSEED \\
\hline 09 & 1423 & C. annuum var. annuum & Aracaju, SE \\
\hline 10 & 1424 & C. chinense & Campos, RJ \\
\hline 11 & 1425 & C.frutescens & Campos, RJ \\
\hline 12 & 1426 & C. baccatum var. pendulum & Campos, RJ \\
\hline 13 & 1489 & C. baccatum var. pendulum & RJ \\
\hline 14 & 1490 & C. baccatum var. pendulum & RJ \\
\hline 15 & 1491 & C. frutescens & RJ \\
\hline 16 & 1492 & C. baccatum var. pendulum & RJ \\
\hline 17 & 1494 & C. baccatum var. pendulum & RJ \\
\hline 18 & 1495 & C. baccatum var. baccatum & RJ \\
\hline 19 & 1496 & C. baccatum var. pendulum & RJ \\
\hline 20 & 1497 & C. chinense & RJ \\
\hline 21 & 1498 & C. chinense & RJ \\
\hline 22 & 1499 & C.baccatum var. pendulum & RJ \\
\hline 23 & 1500 & C.baccatum var. pendulum & RJ \\
\hline 24 & 1501 & C.baccatum var. pendulum & RJ \\
\hline 25 & 1502 & C. annuum var. annuum & México \\
\hline 26 & 1503 & C. annuum var. annuum & México \\
\hline 27 & 1551 & C. chinense & Goiânia, GO \\
\hline 28 & 1553 & C. chinense & Goiânia, GO \\
\hline 29 & 1554 & C. chinense & Goiânia, GO \\
\hline 30 & 1555 & C. chinense & Goiânia, GO \\
\hline 31 & 1556 & C. baccatum var. pendulum & Goiânia, GO \\
\hline 32 & 1557 & C.frutescens & Goiânia, GO \\
\hline 33 & 1558 & C. chinense & Campos, RJ \\
\hline 34 & 1559 & C. annuum var. glabriusculum & Cachoeiras de Macacu, RJ \\
\hline 35 & 1560 & C.frutescens & Cachoeiras de Macacu, RJ \\
\hline 36 & 1561 & C.frutescens & Campos, RJ \\
\hline 37 & 1562 & C. annuum var. annuum & Viçosa, MG \\
\hline 38 & 1565 & C. annuum var. annuum & Viçosa, MG \\
\hline 39 & 1567 & C. annuum var. annuum & Viçosa, MG \\
\hline 40 & 1569 & C. annuum var. annuum & Viçosa, MG \\
\hline 41 & 1570 & C. chinense & $\mathrm{PA}$ \\
\hline 42 & 1571 & C. chinense & Aracaju, SE \\
\hline 43 & 1572 & C. chinense & Aracaju, SE \\
\hline 44 & 1573 & C. baccatum var. pendulum & Duas Barras, RJ \\
\hline 45 & 1575 & C.annuum var. annuum & Campos, RJ \\
\hline 46 & 1577 & C. chinense & Goiânia, GO \\
\hline 47 & 1578 & C. annuum var. annuum & México \\
\hline 48 & 1584 & C. baccatum var. baccatum & Rio das Ostras, RJ \\
\hline 49 & 1585 & C. chinense & Parintins, AM \\
\hline 50 & 1586 & C. chinense & Parintins, AM \\
\hline 51 & 1587 & C. frutescens & Parintins, AM \\
\hline 52 & 1588 & C.frutescens & Parintins, AM \\
\hline
\end{tabular}

Ciência Rural, v.39, n.3, mai-jun, 2009. 
selecionados por revelarem polimorfismo com base em estudo prévio conduzido com indivíduos representando as diferentes espécies utilizadas neste estudo (COSTA et al., 2006).

Os produtos de amplificação foram analisados por eletroforese em gel de agarose $1,2 \%$, submetida a uma corrente de $75 \mathrm{~V}$ por aproximadamente três horas e meia, corados com brometo de etídio e visualizados sob luz ultravioleta no Eagle Eye II. Foram obtidas 96 bandas, sendo que destas, 84 foram polimórficas. Cada banda polimórfica foi caracterizada como presente (1) ou ausente (0) para todos os genótipos, resultando numa matriz de dados binários.

Os dados morfoagronômicos, moleculares e a análise conjunta desses dados (morfoagronômicos + moleculares) foram realizadas utilizando-se o coeficiente de similaridade de Jaccard, com o uso do programa GENES (CRUZ, 2004). As matrizes de distâncias obtidas para cada análise foram agrupadas pelo método hierárquico UPGMA (Unweighted PairGroup Method Using Arithmetic Average) com auxílio do programa Statistica (versão 5.0).

\section{RESULTADOS E DISCUSSÃO}

No dendrograma gerado com base nos dados morfoagronômicos, um corte a $80 \%$ levou à formação de dois grupos principais (Figura 1), o primeiro deles contendo acessos de $\boldsymbol{C}$. annuum, $\boldsymbol{C}$. baccatum e $\boldsymbol{C}$. frutescens e o segundo grupo contendo apenas acessos de $\boldsymbol{C}$. chinense. No primeiro grupo, verificou-se que, embora tenham sido separados por espécie, os acessos formaram dois subgrupos, um deles reunindo acessos de $\boldsymbol{C}$. annuum (Ia), e outro subgrupo reunindo as espécies $\boldsymbol{C}$. baccatum e $\boldsymbol{C}$. frutescens (Ib). Foi observado ainda que, dentro do subgrupo referente à espécie $\boldsymbol{C}$. annuum, dois pares de acessos foram considerados similares (UENF 1381 e 1567, e UENF 1420 e 1421), não sendo possível distingui-los somente com base nas características consideradas nesta avaliação.

No dendrograma gerado com base nas marcas RAPD (Figura 2), um corte a 50\% levou à formação de dois grupos principais. Porém, nesse caso, um grupo foi composto apenas por acessos de $\boldsymbol{C}$. baccatum, variedades pendulum e baccatum, e o outro grupo foi subdividido em três subgrupos, correspondendo às espécies $C$. annuum, $C$. chinense e $\boldsymbol{C}$. frutescens. Dentro do subgrupo formado por $\boldsymbol{C}$. chinense não houve distinção entre os acessos UENF 1551e 1558; UENF 1424, 1555 e 1585; e UENF 1497 e 1498. Assim, essa análise foi menos informativa no que se refere à distinção dos acessos, resultando num maior número de possíveis duplicatas, quando comparada com a análise morfoagronômica.

No terceiro dendrograma (Figura 3), a análise conjunta dos dados morfoagronômicos e moleculares separou os acessos em dois grupos, semelhante ao ocorrido na análise molecular (corte a 60\% da distância genética). Com a associação desses dados, verificouse a diferenciação de todos os acessos analisados, o que não ocorreu nas análises individuais, conforme mencionado anteriormente.

O padrão de agrupamento formado pela análise de caracteres morfoagronômicos (Figura 1) foi bastante distinto dos demais (Figuras 2 e 3) e foi o único que contradisse a proposta de divisão dos complexos gênicos de Capsicum existente na literatura (PICKERSGILL, 1991; ZIJLSTRA et al., 1991). De acordo com essa proposta, as espécies de Capsicum são distribuídas em três complexos gênicos, com base em características morfológicas, citogenéticas e de cruzabilidade. Dentro do complexo gênico C. annuum, que engloba as espécies domesticadas $\boldsymbol{C}$. annuum var. annuum, $\boldsymbol{C}$. chinense e $\boldsymbol{C}$. frutescens, existe uma maior proximidade e maior possibilidade de troca de genes entre essas espécies, o que ocorre também no complexo C. baccatum, que engloba a espécie $\boldsymbol{C}$. baccatum, variedades pendulum, baccatum e praetermissum e também C. tovarii (TONG \& BOSLAND, 1999).

As análises morfoagronômicas, que resultaram no agrupamento de $\boldsymbol{C}$. baccatum com $\boldsymbol{C}$. annuum e $\boldsymbol{C}$. frutescens, separando essas duas últimas espécies de $\boldsymbol{C}$. chinense, permitem supor uma maior proximidade e possibilidade de troca de genes entre acessos de $\boldsymbol{C}$. baccatum, $\boldsymbol{C}$. annuum e $\boldsymbol{C}$. frutescens. O trabalho desenvolvido por CAMPOS (2006) corrobora esta suposição, no qual se verificou a formação de híbridos interespecíficos entre os acessos de $\boldsymbol{C}$. annuum e $\boldsymbol{C}$. baccatum e também entre $\boldsymbol{C}$. frutescens e $\boldsymbol{C}$. baccatum, sendo estes últimos, no entanto, de baixo vigor.

É interessante ressaltar que nos dois primeiros dendrogramas não houve distinção entre alguns acessos, sugerindo a existência de duplicatas, mas, ao se reunirem os dados morfoagronômicos e moleculares, todos os acessos foram distintos entre si, o que permitiu descartar essa hipótese. Isso demonstra não apenas a relevância de se obter o maior número possível de informações sobre os acessos, mas também a complementaridade dessas duas análises tão distintas.

Trabalhando com a diversidade genética baseada em marcadores moleculares e em descritores morfoagronômicos, TEIXEIRA (1996) concluiu que estes últimos foram ineficientes para a distinção 


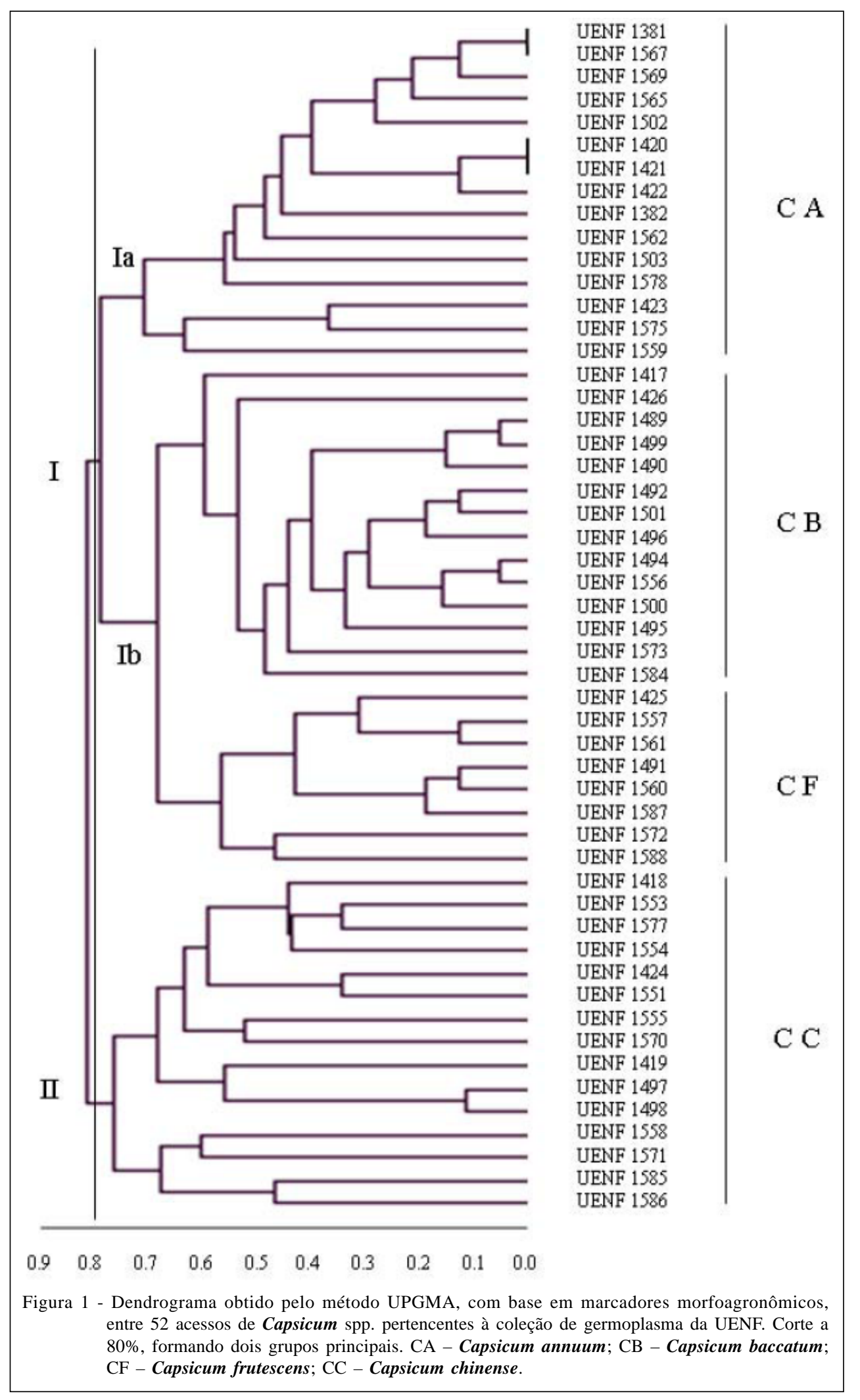

Ciência Rural, v.39, n.3, mai-jun, 2009. 


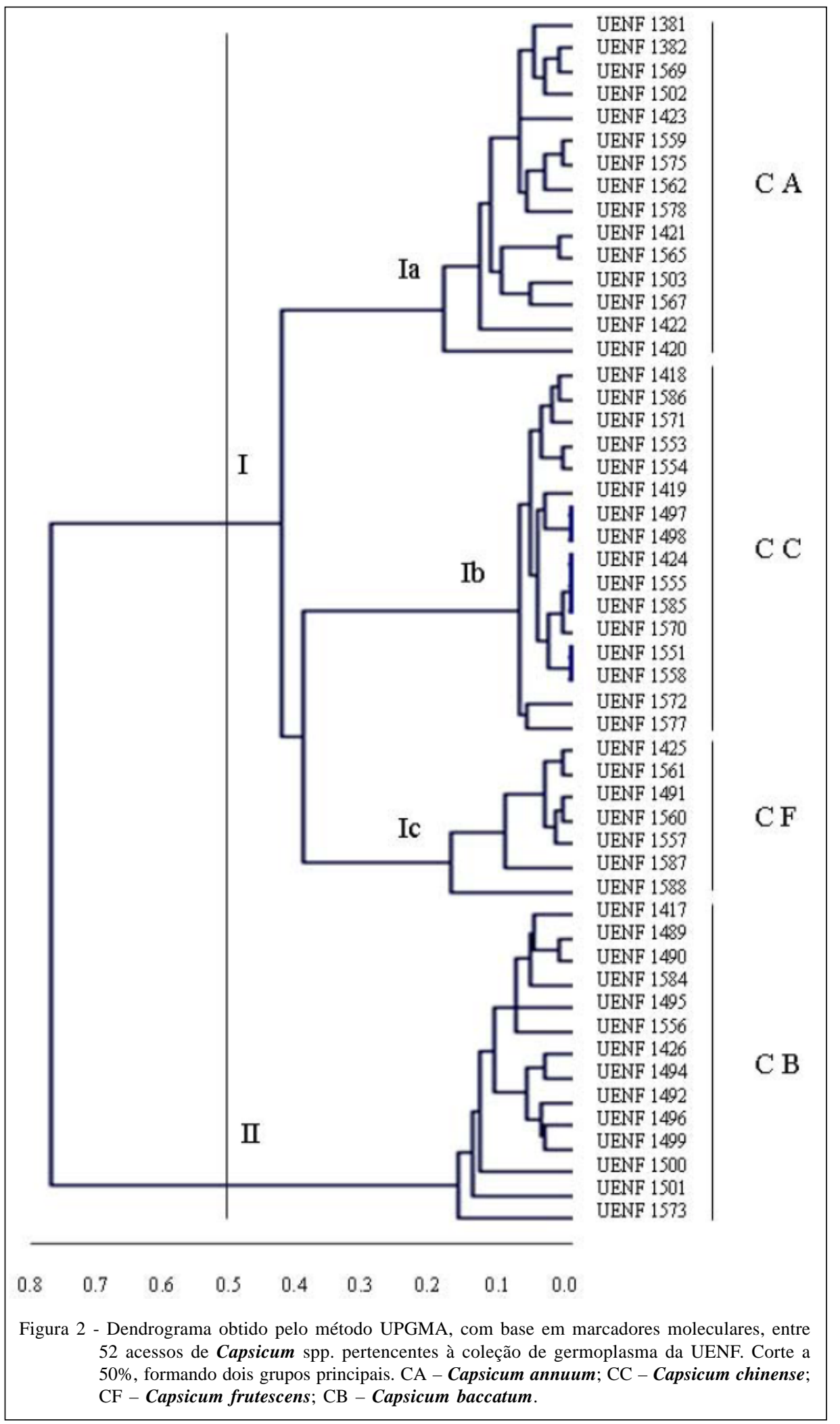

Ciência Rural, v.39, n.3, mai-jun, 2009. 


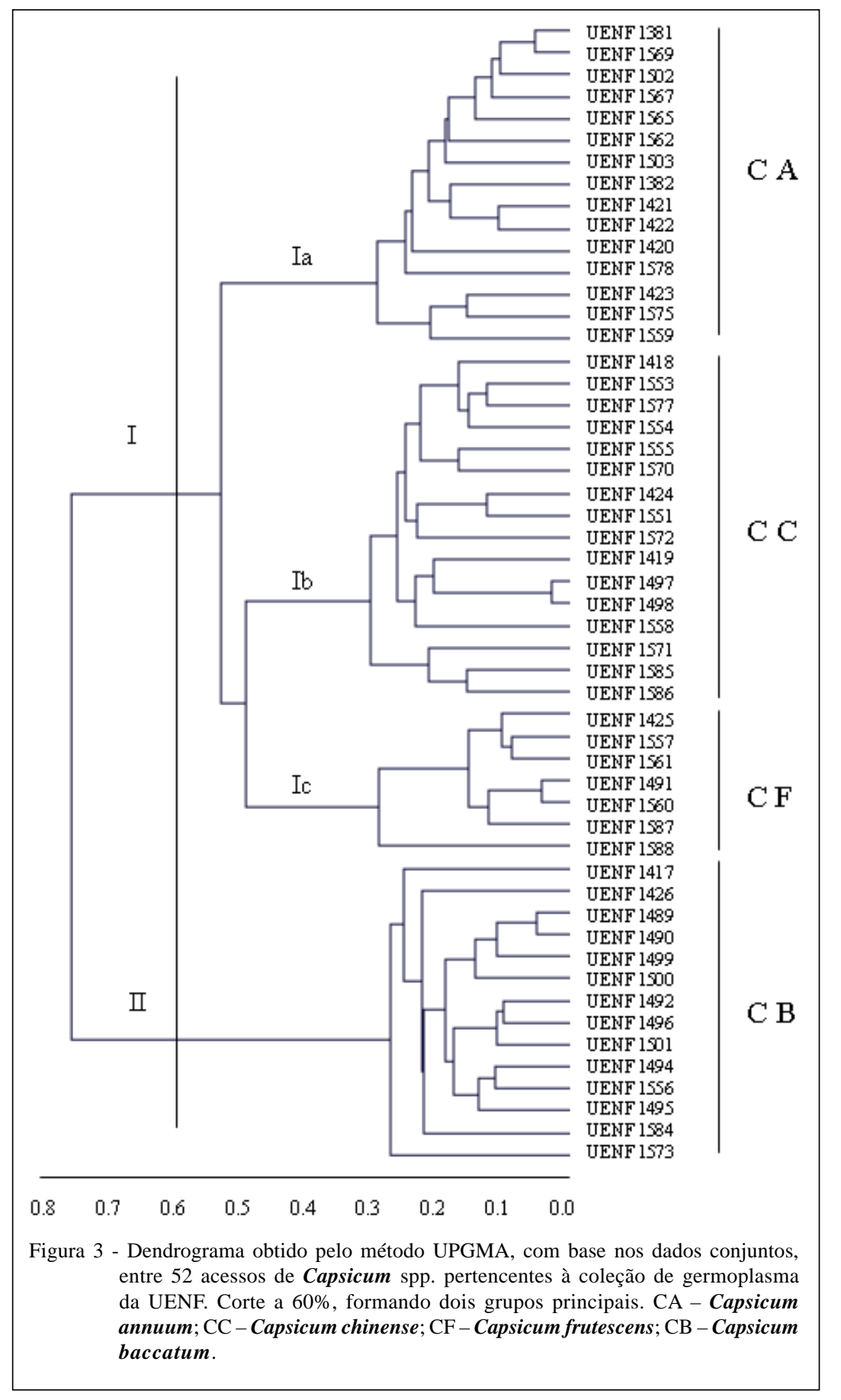

taxonômica. Já BIANCHETTI (1996), utilizando descritores morfoagronômicos e marcadores moleculares, conseguiu agrupar os acessos de acordo com a classificação taxonômica. SUDRÉ et al. (2006) também obtiveram eficiência na distinção taxonômica entre acessos de Capsicum, utilizando descritores morfoagronômicos qualitativos. Nesse trabalho, os autores utilizaram a análise de variáveis multicategóricas e as funções discriminantes de Anderson e conseguiram identificar $100 \%$ das espécies e variedades botânicas estudadas.

\section{CONCLUSÕES}

Considerando os resultados, pôde-se concluir que a caracterização morfoagronômica e os

Ciência Rural, v.39, n.3, mai-jun, 2009. 
marcadores moleculares foram complementares na avaliação da diversidade genética da coleção de Capsicum estudada. A associação desses dados foi fundamental para uma completa distinção dos acessos, bem como para a exclusão da existência de duplicatas na coleção. Esses dados demonstram a importância do uso de diferentes técnicas na caracterização de coleções de germoplasma para o conhecimento e uso dos acessos.

\section{AGRADECIMENTOS}

À Fundação Carlos Chagas de Amparo à Pesquisa do Estado Rio de Janeiro (FAPERJ), pela concessão da bolsa de Mestrado para a primeira autora.

\section{REFERÊNCIAS}

BAOXI, Z. et al. Two RAPD markers linked to a major fertility restorer gene in pepper. Euphytica v.113, p.155-161, 2000.

BASTIANEL, M. et al. Identification of zygotic and nucellar tangerine seedlings (Citrus spp.) using RAPD. Genetics and Molecular Biology v.21, n.1, p.123-127, 1998.

BIANCHETTI, L.B. Aspectos morfológicos, ecológicos e biogeográficos de dez táxons de Capsicum (Solanaceae) ocorrentes no Brasil. 1996. 174f. Tese (Mestrado em Botânica) - Curso de Pós-graduação em Botânica, Universidade de Brasilia.

CAMPOS, K.P. Obtenção, caracterização molecular, morfológica e reprodutiva de híbridos entre espécies de Capsicum. 2006. 145f. Tese (Doutorado em Produção Vegetal) - Curso de Pós-graduação em Produção Vegetal, Universidade Estadual do Norte Fluminense Darcy Ribeiro.

CONTI, J.H. et al. Comparação de caracteres morfológicos e agronômicos com moleculares em morangueiros cultivados no Brasil. Horticultura Brasileira, v.20, n.3, p.419-423, 2002.

COSTA, F.R. Diversidade genética entre acessos de Capsicum spp. com base em marcadores RAPD. 2004. 62f. Tese (Mestrado em Produção Vegetal) - Curso de Pósgraduação em Produção Vegetal, Universidade Estadual do Norte Fluminense Darcy Ribeiro. Data de acesso: 12/09/2008. Online. Disponível em: http://www.uenf.br/Uenf/Pages/CCTA/ ProdVegetal/

COSTA, F.R. et al. Genetic diversity among Capsicum accessions using RAPD markers. Crop Breeding and Applied Biotechnology, v.6, p.18-23, 2006.

CRUZ, C.D. Programa Genes (versão Windows): aplicativo computacional em genética e estatística. Viçosa: UFV, 2004. 648p.

CRUZ, C.D.; CARNEIRO, P.C.S. Modelos biométricos aplicados ao melhoramento genético. Viçosa: UFV, 2003. 585p.

DOYLE, J.J.; DOYLE, J.L. Isolation of plant DNA from fresh tissue. Focus, v.12, p.13-15, 1987.

ENGLE, L.M. et al. Analysis of genetic diversity of Capsicum spp. (pepper) using random amplified polymorphic DNA analysis. Journal of Agricultural Research of China, v.50, n.4, p.29-42, 2001.

HE, G. et al. Analysis of genetic diversity in a sweet potato (Ipomea batata) germplasm collection using DNA amplification evidence. Genome, v.39, p.1133-1141, 1995.

ILBI, H. RAPD markers assisted varietal identification and genetic purity test in pepper, Capsicum annuum. Scientia Horticulturae, v.97, p.211-218, 2003.

INAI, S. et al. Genetic analysis of stunted growth by nuclearcitoplasmic interaction in interespecific hybrids of Capsicum by using RAPD markers. Theoretical and Applied Genetics, v.87, p.416-422, 1993.

INOUE, A.K.; REIFSCHNEIDER, J.B. Caracterização da coleção de germoplasma de Capsicum do CNPH. Horticultura Brasileira, v.7, n.1, p.10-18, 1989.

IPGRI. Descriptores para Capsicum (Capsicum spp.). Roma, 1995. 51p.

KALOO, G. et al. RAPD protocol for tagging of fertility restorer and male sterility genes in chilli (Capsicum annuum L.) Vegetable Science, v.29, n.2, p.101-105, 2002.

LIN, C.C. et al. Application of random amplified polymorphic DNA (RAPD) markers on cultivar identification of Capsicum annuum L. Seed and Nursery, v.2, n.1, p.19-35, 2000.

LIVINGSTONE, K.D. et al. Genome mapping in Capsicum and the evolution of structure in the Solanaceae. Genetics, v.152, p.1183-1202, 1999.

PARAN, I. et al. An integrated genetic linkage map of pepper (Capsicum spp.). Molecular Breeding, v.13, p.251-261, 2004.

PICKERSGILL, B. Cytogenetics and evolution of Capsicum L. In: TSUCHIYA, T.; GUPTA, P.K. Chromosome engineering in plants: genetics, breeding, evolution. Amsterdam: Elsevier, 1991. Part B, p.139-160.

PRINCE, J.P. et al. A survey of DNA polymorphism within the genus Capsicum and the fingerprinting of pepper cultivars. Genome, v.38, p.244-251, 1995.

RAMOS, S.R.R. et al. Caracterização preliminar de acessos de Capsicum do Banco ativo de germoplasma da UENF. Horticultura Brasileira, v.19, n.2, p.270, 2001.

RAMOS, S.R.R. et al. Divergência genética em acessos de pimenta coletados no Rio de Janeiro. Horticultura Brasileira, v.18, p.673-674, 2000.

RODRIGUEZ, J.M. et al. Variation among and within Capsicum species revealed by RAPD markers. Theoretical and Applied Genetics, v.99, p.147-156, 1999.

RUANET, V.V. et al. The use of a self-organizing feature map for the treatment of the results of RAPD and ISSR analyses in studies on the genomic polymorphism in the genus Capsicum L. Russian Journal of Genetics, v.41, n.2, p. 202-210, 2005.

Ciência Rural, v.39, n.3, mai-jun, 2009. 
SUDRÉ, C. P. et al. Divergência genética entre acessos de pimenta e pimentão utilizando técnicas multivariadas. Horticultura Brasileira, v. 23, n. 1, p. 22-27, 2005.

SUDRÉ, C.P. et al. Variáveis multicategóricas na determinação da divergência genética entre acessos de pimenta e pimentão. Horticultura Brasileira, v. 24, n. 1, p. 88-93, 2006.

SUGITA, T. et al. Rapid construction of a linkage map using high-efficiency genome scanning/ AFLP and RAPD, based on an intraspecific, doubled-haploid population of Capsicum annuum. Breeding Science, v.55, p.287-295, 2005.

TEIXEIRA, R. Diversidade em Capsicum: análise molecular, morfoagronômica e química. 1996. 81f. Tese (Mestrado em Genética e Melhoramento) - Curso de Pós- graduação em Genética e Melhoramento, Universidade Federal de Viçosa.

TONG, N.; BOSLAND, P.W. Capsicum tovarii, a new member of the Capsicum baccatum complex. Euphytica, v.109, p.7177, 1999

VAZQUEZ, F.J.L.H. et al. RAPD fingerprinting of pepper ( $\boldsymbol{C}$. annuum L.) breeding lines I. Capsicum and Eggplant Newsletter, v.16, p.37-40, 1996.

WILLIAMS, J.G.K. et al. DNA polymorphism amplified by arbitrary primers are useful as genetic markers. Nucleic Acids Research, v.18, p.6531-6535, 1990.

ZIJLSTRA, S. et al. Pollen tube growth in interspecific crosses between Capsicum species. HortScience, v.26, p.585-586, 1991. 